\title{
Discours
}

Revue de linguistique, psycholinguistique et

informatique. A journal of linguistics, psycholinguistics and computational linguistics

$18 \mid 2016$

Varia

\section{Referential Choices and Specific Language Impairment: Sensitivity to Contrast Levels and Grammatical Role}

\section{Maja Stegenwallner-Schütz and Flavia Adani}

\section{(QpenEdition Journals}

Electronic version

URL: http://journals.openedition.org/discours/9179

DOI: $10.4000 /$ discours. 9179

ISSN: 1963-1723

Publisher:

Laboratoire LATTICE, Presses universitaires de Caen

\section{Electronic reference}

Maja Stegenwallner-Schütz and Flavia Adani, « Referential Choices and Specific Language

Impairment: Sensitivity to Contrast Levels and Grammatical Role», Discours [Online], 18 | 2016, Online since 16 September 2016, connection on 21 April 2019. URL : http://journals.openedition.org/ discours/9179; DOI : 10.4000/discours.9179 

Revue de linguistique, psycholinguistique et informatique

\section{Referential Choices \\ and Specific Language Impairment: Sensitivity to Contrast Levels and Grammatical Role}

Maja Stegenwallner-Schütz

Linguistics Department

University of Potsdam

Flavia Adani

Linguistics Department

University of Potsdam 



\title{
Referential Choices \\ and Specific Language Impairment: Sensitivity to Contrast Levels and Grammatical Role
}

\author{
Maja Stegenwallner-Schütz \\ Linguistics Department \\ University of Potsdam \\ Flavia Adani \\ Linguistics Department \\ University of Potsdam
}

\begin{abstract}
Speakers' referential choices differ in the degree of explicitness, ranging from very explicit expressions (such as lexical NPs, e.g., the boy) to less explicit expressions (such as pronouns, e.g., he, and null elements). We examine the referential choices of children with Specific Language Impairment (SLI), in order to differentiate between the linguistic and pragmatic abilities involved in the selection of appropriate referring expressions. Existing findings on referential choices by children with SLI are currently inconsistent and have mainly been reported based on narratives. We used an elicited production task to manipulate the referent's accessibility by means of two factors: (a) contexts that instantiate different levels of contrast (one vs. two contrasts) and (b) the grammatical role of the expression (subject vs. object). We show that children with SLI and typically developing controls produce more explicit expressions for increased contrast levels and for objects than for subjects. Although children with SLI modify the explicitness of their referring expressions according to the accessibility of referents as typically developing children do, we also find varying production rates between the groups. We discuss how these differences in production rates surface as a consequence of language impairment, although the explicitness of referential choices remains otherwise largely unaffected.
\end{abstract}

Keywords: Specific Language Impairment, referential choices, contrast, grammatical role, discourse accessibility, elicited production, sentence production, referring expressions

\section{Introduction}

In the process of planning an utterance, speakers need to select an expression with which to refer to entities in the world. They select, consciously or not, from a range of referring expressions that vary in their degree of explicitness. Names and descriptions are very explicit expressions. They are very informative with regard to their purpose of uniquely identifying a corresponding referent in the world, and they are realized as lexical NPs, such as Jonas, the boy, or a boy at school, all of which can be produced to refer to a certain boy named Jonas. Less explicit expressions such as pronouns (e.g., he bim) or even phonologically silent elements are less informative. They can be appropriately used when the referent is currently in the focus of attention of the speaker and the addressee (Gundel et al., 1993), and hence, they are interpretable by the addressee (see Arnold, 2008; Gatt et al., 2014, for overviews). 
Traditionally, the explicitness of an expression is viewed as a reflection of the discourse status of the referent (Ariel, I990; Chafe, 1976). Appropriate referential choices depend on a speaker's modeling of the referent's discourse status (Arnold, 2008; Brennan, 1995; Chafe, 1976; Grosz et al., 1995) and on the speaker's judgments about the degree of explicitness that is necessary for the expression to be pragmatically appropriate in a given situation (Ariel, 200I; Gundel et al., I993; Gundel et al., 2012). For example, the sentences $A$ boy from school writes beautiful letters, Jonas writes beautiful letters, or He writes beautiful letters can all express the same meaning, but depending on the familiarity of the speaker and the addressee with the referent, the use of the pronoun is pragmatically appropriate only, when the referent has been introduced before. Likewise, it would be odd to refer with a description such as $a$ boy from school to a person that both interlocutors are familiar with. Children have to master a complex task when sorting out the relative contributions of the linguistic and pragmatic factors that influence the selection of appropriate expressions in order to arrive at adult-like referential choices (Gundel \& Johnson, 2013; Gundel et al., 2007; Hendriks et al., 20I4). Little is known about how the linguistic and pragmatic abilities needed for appropriate referential choices are affected by developmental language disorders (Norbury \& Bishop, 2003).

In this paper, we focus on Specific Language Impairment (SLI), which is a developmental disorder that predominantly affects the acquisition and processing of language, predominantly within the domain of morpho-syntax (Bishop, 1997; Leonard, 1998). Children diagnosed with SLI have an age-appropriate IQ, as well as normal sensory, neurological, and social-emotional abilities, implying that there is no apparent source of their language difficulties beyond the grammatical system and/or cognitive resources involved in language processing, for example, verbal working memory (Leonard, 1998; van der Lely, 2005). Under an account of SLI that locates the language impairment specifically at the level of grammar (Schaeffer, 20I2; van der Lely, 1997), referential choices would not be expected to be affected by the grammatical impairment because they are viewed as pragmatic choices (cf. Arnold, 2008).

However, studies that have examined referential choices of children with SLI have found differences between the explicitness of the expressions produced by children with SLI and those produced by typically developing children. At the same time the referential choices of children with SLI reveal sensitivity to similar discourse factors (such as newness and givenness) as those observed with typically developing children (de Weck \& Jullien, 2013; Norbury \& Bishop, 2003; van der Lely, 1997). These studies have mainly elicited narratives, in which the accessibility status of the referents can vary greatly. Our study complements and enriches the existing studies using an elicitation task that allows us to control for previous mentioning and the presence of potential referents in the linguistic and visual contexts.

We further examine the referential choices of children with SLI because referential choices have important theoretical implications regarding the specificity of the developmental disorder and which linguistic and pragmatic abilities are involved 
in the selection of an appropriate referring expression with regard to its degree of explicitness (Stegenwallner-Schütz \& Adani, 20I4). We aim at identifying common sources that can explain referential choices by children with SLI, which might be affected by their grammatical impairment. To this end, we assess the explicitness of referring expressions produced by children with SLI as determined by the level of contrast in the context of an utterance and by the grammatical role of the expression in the sentence.

Contrasts have been shown to influence the explicitness of children's expressions from very early on in life (Graf et al., 2015; Wittek \& Tomasello, 2005; see Allen et al., 20I5, for an overview). Contrasts typically lead to the production of very explicit expressions (cf. Allen et al., 20I5). As an information-structural category, contrasts involve the presence of an alternative referent in the context of an utterance (Molnár, 2006). The advantage of contrast effects is that they do not necessarily require speakers to take the addressee's perspective into account. This is an advantage for the study of referential choices because perspective-taking appears to be challenging for young children (Hendriks et al., 20I4; Kail \& Hickmann, I992; Campbell et al., 200o). Contrast effects also occur independently of higher order theory of mind abilities (cf. De Cat, 2013; Gundel \& Johnson, 2013; Gundel et al., 2007). This is particularly relevant if we consider that children with SLI have been claimed to lag behind typically developing children with respect to theory of mind abilities (Farrant et al., 2006; cf. Miller, 2004).

While contrasts influence the accessibility of a referent through the prior discourse (mention of another referent) and perceptual factors (availability of another referent in the perceptual context, for example, the visual context), the relation between grammatical role and the explicitness of an expression is based on linguistic categories such as subject and object. Subjects tend to be realized with less explicit expressions more often than objects (Du Bois, 1987).

With the inclusion of contrast and grammatical role, we focus on speaker-oriented discourse factors (cf. Arnold, 2008) and aim to differentiate between the influence of predominantly pragmatic factors and the influence of predominantly grammatical factors on the referential choices by children with SLI. Anticipating our results, we do not observe major differences in the production of lexical NPs between children with SLI and typically developing children with respect to contrast levels and grammatical role. These data support the claim that children with SLI are not impaired in assessing the accessibility of referents as determined by contrasts and grammatical role in the discourse. We relate the subtle differences that we do find to difficulties in maintaining the activation of referents in the discourse representation.

\subsection{Referential choices in typical development}

As pointed out in the introduction, there is a direct and gradual correspondence between the explicitness of an expression and the accessibility of the corresponding referent (the antecedent) in the speaker's current discourse model (Ariel, 1990; Gundel 
et al., 1993). The more accessible a referent is, the less explicit an expression needs to be and still be appropriately used in a given situation. In other words, the appropriate selection of an expression relies heavily on the speaker's own mental representation of discourse. Very explicit referring expressions are appropriately produced as references to inaccessible referents. These are referents which have little to no activation in the current discourse representation before being mentioned. This is the case, for example, when a speaker is introducing a new referent to the discourse. When the referent moves into the focus of attention of the speaker and/or the addressee, this referent becomes gradually more and more accessible. Therefore, speakers tend to produce less explicit expressions, for example, pronouns or even phonologically silent elements (i.e., omissions, which we term null elements hereafter), for maintaining reference (Ariel, 1990; Du Bois, 1987; Gundel et al., 1993).

Three-year-old children already show sensitivity to the correspondence between a referential expression and the discourse status that the expression signals (Gundel \& Johnson, 2013; Gundel et al., 2007). Similarly to adults, children produce more explicit expressions for inaccessible referents and less explicit expressions for accessible referents, for example, by producing pronouns for maintaining reference to a previously introduced entity (Allen et al., 2008; Campbell et al., 2000; Hendriks et al., 20I4; Matthews et al., 2006). Already at age 2.5, children respond to specific questions about objects (which have been previously introduced) such as What bappened to $X$ ? with pronouns or null elements (Wittek \& Tomasello, 2005). These findings do not necessarily imply that young children make adult-like referential choices in all respects. There is a great deal of evidence that children overproduce expressions that are less explicit than those favored by adults in the same situations (Campbell et al., 2000; De Cat, 20II and 20I3; Hendriks et al., 20I4; Hickmann et al., 1996; Matthews et al., 2006; Serratrice, 2008; Wittek \& Tomasello, 2005). In particular, when introducing new referents or reintroducing a referent after having referred to another referent, children often overproduce pronouns (or definite lexical NPs) which do not efficiently identify the referent in the given situation. These expressions are sometimes ambiguous because of additional potential referents in the discourse (Hendriks et al., 20I4). This behavior is generally considered a failure to sufficiently take into consideration the addressee's perspective (De Cat, 201 and 20I3; Hendriks et al., 20I4). In this paper, we focus on two factors that have been shown to influence children's referential choices: contrast and grammatical role.

\subsubsection{Effects of contrasts}

11 If there is at least one other referent active in the discourse that becomes perceptually salient or is formally introduced into the discourse at some point, that referent becomes a competitor to any other active referent and the accessibility of the referents decreases (Ariel, 1990: 28). When the focus of attention is distributed among competing referents, adult speakers are more likely to refrain from the production of pronouns for previously introduced referents and tend to produce more explicit expressions (e.g., lexical NPs) (Arnold \& Griffin, 2007; Fukumura et al., 20Io). An increase in more 
explicit expressions in the presence of a competitor has been observed when another referent has been mentioned (Arnold \& Griffin, 2007) or is perceptually available in the context (Fukumura et al., 20Io). This increase in lexical NP productions is considered to constitute evidence for competition effects. These effects have been observed in situations where pronominal reference would have been unambiguous and, hence, the lexical NPs are unnecessary to avoid ambiguous reference (Arnold, 2008).

Similar to adults, children also produce very explicit referring expressions in situations where a potential competitor is perceptually present (Serratrice, 2008 and 2013). Even 2.5-year-olds have been shown to produce lexical NPs when a contrast between potential referents has been introduced in a preceding question (for example, Do we need a mop? - No, a broom; Wittek \& Tomasello, 2005). Taken together, there is ample evidence that contrast affects the accessibility of referents in children's discourse representations and leads to the production of more explicit expressions.

\subsubsection{Effects of grammatical role}

The grammatical role of a referent constitutes one of the linguistic factors that robustly influences the explicitness of an expression. Subjects tend to be given information (Chafe, 1976) and they generally tend to be more accessible than objects. This may also have to do with the fact that subjects are typically the topics of a sentence and speakers often organize their utterances in such a way that they can continue to talk about them in the following utterance (Brennan, 1995). Adult speakers prefer to produce pronouns when referring back to a subject antecedent of a preceding sentence (Arnold, 200I; Brennan, 1995). In the same vein adults generally realize subjects of transitive sentences more often as pronouns than they do objects (Du Bois, 1987). Five-year-old children also exhibit a preference for realizing subjects of transitive sentences as pronouns (Theakston, 20I2). This preference appears to be so strong that the 5 -year-olds in Theakston's (2012) study even realized inaccessible subjects (i.e., not mentioned in the preceding five sentences) as pronouns instead of lexical NPs. However, the preference for pronominalizing a subject is not evident when the subject is contrasted (Graf et al., 2015). Graf et al. (2015) showed that 3-year-olds preferred to realize contrasted subjects as lexical NPs and preferred to produce more explicit expressions for contrasted than for non-contrasted subjects. Bittner (2007) proposes for German that the grammatical role of the referent influences the selection preference among less explicit expressions (i.e., null elements, personal pronouns, and demonstrative pronouns) from age 3.5.4.5 on, when grammatical role and animacy properties of nominal constituents are considered. In sum, the grammatical role of a referent is another factor that strongly influences children's referential choices.

\subsection{Referential choices by children with SLI}

By definition, pragmatic abilities are considered to be spared in children with Specific Language Impairment (Schaeffer, 2012; van der Lely, 1997). However, there is inconsistent evidence as to whether children with SLI behave like typically developing 
children in assessing the discourse status of referents and selecting the appropriate referential form. The explicitness of expressions produced by children with SLI has mainly been examined in relation to the information status of referents (givenness, newness). For example, children with SLI have been shown to prefer lexical NPs for (re)introducing referents just as chronological-age-matched typically developing children do (de Weck \& Jullien, 2013; Norbury \& Bishop, 2003; van der Lely, 1997), and they produce pronouns for maintaining reference to previously mentioned referents (Norbury \& Bishop, 2003; van der Lely, 1997). Children with SLI also appear to show a sensitivity to the grammatical role of the referent (Schelletter \& Leinonen, 2003).

Some studies report differences between children with SLI and typically developing children with respect to the explicitness of the selected expressions. De Weck and Jullien (2013) found children with SLI (aged 6-9 years) to produce fewer indefinite lexical NPs as introductions compared to age-matched controls and, unsurprisingly, fewer appropriate introductions when only indefinite lexical NPs would be considered as appropriate. The differences point towards a problem with taking the addressee's perspective into account in SLI (de Weck \& Jullien, 20I3). Consistent with this explanation, children with SLI also performed more poorly in referential communication tasks and tended to produce underinformative utterances (Bishop \& Adams, 199I; Davies et al., 2016).

Moreover, Norbury and Bishop (2003) reported that children with SLI produced more lexical NPs relative to pronouns for maintaining reference to an entity than their age-matched controls. They also produced more ambiguous pronouns, meaning that they produced fewer lexical NPs in contexts where more than one referent was active and, hence, an ambiguity could arise. Even when controlling for the differences in language age, van der Lely (1997) found that children with SLI produced more lexical NPs than controls in contexts where at least two referents were present and which required a reintroduction of the referent.

Taken together, the findings by Norbury and Bishop (2003) and van der Lely (1997) indicate that children with SLI sometimes select less explicit expressions than typically developing controls while in other situations they use expressions that are more explicit. Although the greater production rate of ambiguous pronouns may point towards an inability to sufficiently take the addressee's perspective into consideration, an ignorance of the addressee's perspective cannot account for the overexplicit responses because the children produce expressions that are even more informative than those of controls. Rather, the performance of the children with SLI could be indicative of difficulties with assessing or maintaining the activation status of referents.

When considering groups of children with SLI of different ages, de Weck and Jullien (2013) discovered that a difference in the production of indefinites observed between younger children with SLI (aged 6-7, and 8-9 years) and age-matched controls was absent among older children with SLI (aged IO-II years). When comparing the 
referential choices by children with SLI to those of language-matched controls, children with SLI mainly performed comparably to controls (van der Lely, 1997). These findings highlight the importance of considering developmental changes in typical and atypical development.

Overall, children with SLI exhibit similar preferences in their referential choices compared to typically developing children. They base the explicitness of the expressions on the activation status of referents in the discourse in a way that is consistent with the direct correspondence between a referring expression and the activation status that the expression signals, although with some exceptions (see Norbury \& Bishop, 2003; van der Lely, 1997).

Narratives cannot entirely manipulate or control the accessibility of referents because the activation status of each referent changes with each individual referential choice that the narrator makes. This motivated us to use a controlled experimental design in which we could control for the linguistic and perceptual accessibility of the referents whom the participants have to refer to for each elicited response.

With this work we want to discuss two accounts that could potentially explain why referential choices could be impaired in SLI. Hendriks et al. (2014) provide an account of the production of ambiguous pronouns by healthy elderly adults. They suggest that a decrease in working memory abilities is reflected in difficulties maintaining the activation status of a referent in the discourse model and this in turn leads to an increase in less explicit expressions. Working within a modular account, Schaeffer (2012) concludes that a difference between children with SLI and their peers in a pragmatic task must be explicable in terms of their language difficulties. This account predicts that the performance of children with SLI should be comparable to that of younger, typically developing children. It also predicts that children with SLI might be vulnerable with regard to the grammatical factor of grammatical role rather than the pragmatic factor of contrast. In the current study, we were interested in comparing children with SLI and typically developing children in regard to their sensitivity to increased contrast levels while otherwise controlling for the accessibility of the referents, as well as regarding the influence of the grammatical role of the referent on the explicitness of an expression.

\section{This study}

We examine the realization of relative clause heads in experimentally controlled discourse contexts which were carefully designed in terms of the visual material as well as the elicitation questions. We used the elicited production task by Zukowski (2009), which was adapted for German by Adani et al. (2016). Since restrictive relative clauses refer by definition to a unique referent, the production of different referring expressions as relative clause head nouns cannot be due to ambiguity avoidance. Instead, any difference in the explicitness of the head noun must be attributable to differences in the activation status of referents. 
By comparing the group of children with SLI to typically developing children, we aim at assessing whether their referential choices are influenced by contrast and grammatical role to a similar extent as expected on the basis of their chronological age or whether they exhibit preferences that resemble those of younger typically developing children.

With regard to contrast, we predict that an increase in the level of contrast should lead to more explicit referring expressions, i.e., more lexical NPs being produced as head nouns and, conversely, to fewer occurrences of pronominal and null elements in the two-contrast context compared to the one-contrast context (cf. Serratrice, 2008 and 2013).

In addition, we also predict that the grammatical role of the referent (i.e., subject vs. object) will influence the explicitness of reference. On the basis of children's and adults' preference for pronominalizing subjects (Theakston, 20I2), we expect more explicit expressions (e.g., full lexical NPs) as references to object referents compared to subject referents.

In our analysis, we also consider developmental changes in the preference for different types of expressions. On the basis of previous studies, we expect age effects to reflect that older children in general produce more lexical NPs than younger children (Bittner, 2007; Serratrice, 2008).

Turning to children with SLI, we aim at distinguishing between the influences of pragmatic vs. grammatical factors on the explicitness of referring expressions. Specifically, if children with SLI have difficulties maintaining the activation status of referents in their discourse representation, we predict that they will use more lexical NPs compared to controls (van der Lely, 1997). If children with SLI process the contrasting information differently from typical development, we would expect them to differ with respect to the effect of contrast levels. If children with SLI have difficulties with the grammatical role, we would expect them to be insensitive to the prominence the grammatical roles are associated with. Assuming a tendency to overproduce explicit referring expressions (van der Lely, 1997), we predict them to differ from typically developing children on subjects rather than on objects, because subjects are typically realized with less explicit expressions (Brennan, I995; Theakston, 2012; Graf et al., 2015).

\subsection{Participants}

Seventy-two typically developing children and I2 children with SLI participated in our study. All participants were monolingual speakers of German. The typically developing children were recruited from day care centers and primary schools in the Potsdam area (Brandenburg, Germany). We recruited the children with SLI from speech and language therapy centers and day care centers with staff trained in language intervention programs in the Potsdam and Berlin areas. For all children, we obtained the written informed consent of the parents. 
The typically developing children had a chronological age ranging from 4;0-9;8 and were divided into groups of 4-year-olds $(n=18), 5$-year-olds $(n=7), 6$-yearolds $(n=19), 7$-year-olds $(n=13), 8$-year-olds $(n=7)$, and 9-year-olds $(n=8)$. We ensured via parental questionnaires that they neither have nor had a language impairment nor a familial risk for one.

The children with SLI had a mean chronological age of 6.4 years (ranging from 4;7-IO;II). All children with SLI had reported language impairment. In addition, we also assessed their cognitive and language abilities with a battery of standardized tests in German. All children with SLI had a normal IQ $(>80)$ and did not fit the exclusion criteria of Leonard (1998). The children with SLI performed below their age norm $(-$ I $S D)$ on at least two tests in the following battery: comprehension of word order variation, pronouns, and relative clauses (Siegmüller et al., 2oII), productive vocabulary (Kauschke \& Siegmüller, 2002, for participants younger than 6 years; Glück, 2007, for participants who were 6 years old or older), letter and digit recall (Grob et al., 2009), and meta-language (Petermann et al., 20Io). Table I provides individual overviews of the scores of the children with SLI. We also calculated the average language age of the children with SLI, which was 5.2 years (ranging individually from 4 to 9 years). The language age was calculated as an average of the age-corrected scores of the morpho-syntactic tests (word order, pronouns, relative clauses), the letter and digit recall test, and the meta-language test.

The data of the typically developing children were analyzed using a developmental trajectory (Thomas et al., 2009). Unfortunately, our sample of children with SLI was not large enough to warrant a similar developmental analysis for our affected population. Therefore, the data collected from children with SLI were analyzed as a single group. In order to match the SLI and control groups, we calculated the SLI group's mean chronological age and used this as a zero point on which we centered the typically developing children according to their chronological ages. We repeated this procedure for the language age of the SLI group. This allows for two comparisons: comparing the SLI group to the typical development on the basis of the chronological age and on the basis of the language age of the children with SLI. Naturally, the chronological age equals the language age for the typically developing children, and the children with SLI are treated as being younger according to their language ages.

\subsection{Experimental design and materials}

We manipulated two variables: the contrast level of the elicitation question and the visual stimulus (two levels: one contrast vs. two contrasts) and the grammatical role of the targeted referring expression (two levels: subject vs. object). Table 2 shows the experimental design and provides example materials that we are going to use for illustration. Contrasts were expressed through the presence of another potential referent of the same kind as the targeted referent and through contrasting color 


\begin{tabular}{|c|c|c|c|c|c|c|c|c|c|c|c|c|c|}
\hline 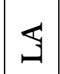 & $\lambda$ & $\wedge$ & $\sim$ & $a$ & $n$ & + & + & $\sim$ & $n$ & 0 & $\sigma$ & + & $\sim$ \\
\hline$\frac{n}{\mathscr{d}}$ & + & 0 & $\circ$ & $\stackrel{a}{\infty}$ & $q$ & $\stackrel{m}{m}$ & $\stackrel{\sim}{m}$ & 7 & $f$ & $\stackrel{\circ}{1}$ & $\stackrel{.}{m}$ & $\approx$ & $\approx$ \\
\hline$\stackrel{\hat{\underbrace{}}}{\hat{\omega}}$ & 2 & $m$ & - & $\wedge$ & $\infty$ & $\grave{\infty}$ & 0 & \pm & $\stackrel{\infty}{\infty}$ & + & $\stackrel{\circ}{\circ}$ & $a$ & $\wedge$ \\
\hline 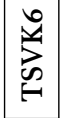 & + & : & $\stackrel{\infty}{\infty}$ & $\tilde{\sigma}$ & त & $\stackrel{\infty}{\infty}$ & $\vec{\infty}$ & $\approx$ & $\dot{m}$ & \pm & $\stackrel{\circ}{m}$ & $\infty$ & $\stackrel{m}{2}$ \\
\hline 芹 & + & ס्र & స్ & స్ & \pm & $\approx$ & $\stackrel{\circ}{\wedge}$ & \pm & in & $\widehat{m}$ & $\approx$ & $\bar{n}$ & \pm \\
\hline 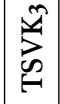 & + & $\tilde{f}$ & 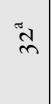 & $\stackrel{ \pm}{\sim}$ & $f$ & $\stackrel{ \pm}{m}$ & F & $\tilde{f}$ & 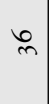 & 7 & है & $\hat{\lambda}$ & in \\
\hline $\begin{array}{l}\sum \\
\infty \\
1 \\
\hat{\omega} \\
\hat{\Xi}\end{array}$ & $\infty$ & 6 & $\wedge$ & $\therefore$ & 6 & $\circ$ & 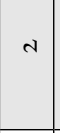 & 6 & 6 & $a$ & 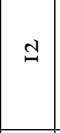 & $\infty$ & $=$ \\
\hline 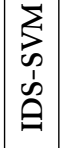 & $\infty$ & $\exists$ & $\exists$ & $\circ$ & $\therefore$ & $\infty$ & $\approx$ & $a$ & $\wedge$ & $a$ & $a$ & $\wedge$ & $n$ \\
\hline 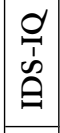 & $\stackrel{d}{a}$ & $\bar{\alpha}$ & 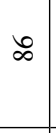 & $\asymp$ & $\Xi$ & $\stackrel{+}{0}$ & $\vec{o}$ & ஃ & $\alpha$ & 号 & $\stackrel{\infty}{\alpha}$ & $\hat{\infty}$ & $\cong$ \\
\hline & $q$ & $\infty$ & - & $\exists$ & $\wedge$ & $m$ & $\wedge$ & $m$ & $\sim$ & 0 & $\infty$ & a & $m$ \\
\hline 焉 & $\lambda$ & $\infty$ & $\infty$ & $\circ$ & $\sim$ & $n$ & + & 6 & 6 & $a$ & $n$ & $n$ & 0 \\
\hline 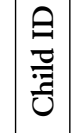 & & 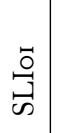 & 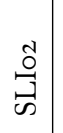 & $\begin{array}{l}\hat{0} \\
\stackrel{⿹}{⿹}\end{array}$ & 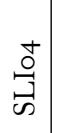 & $\stackrel{0}{\Theta}$ & 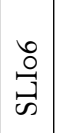 & $\begin{array}{l}\hat{0} \\
\stackrel{\omega}{G} \\
-1\end{array}$ & $\begin{array}{l}\infty \\
0 \\
⿱ 乛 \\
\omega\end{array}$ & $\mid \begin{array}{c}a \\
9 \\
\vec{\omega}\end{array}$ & $\stackrel{9}{\stackrel{9}{g}}$ & 咅 & 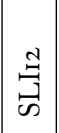 \\
\hline
\end{tabular}

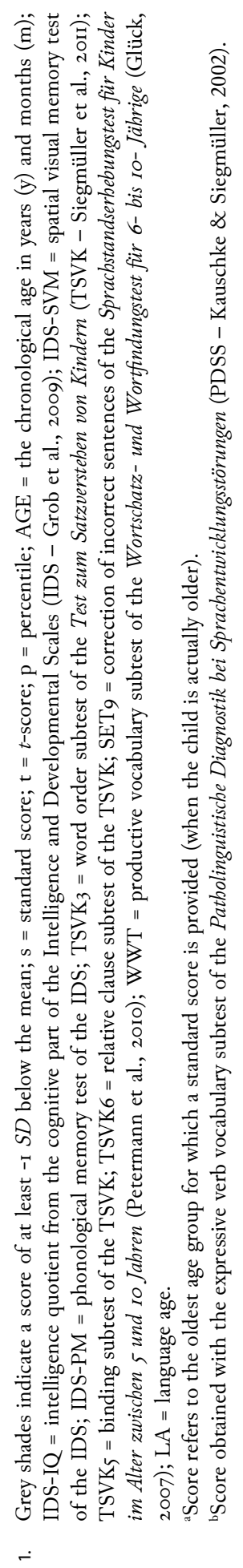


changes or the additional action of being photographed. For the one-contrast context, a single elicitation question (for example, Which boy is now purple?) was used in combination with a visual stimulus that depicted two potential referents, for example, two boys who could be distinguished by the actions they perform. In our example, one boy is touching a cow and the other boy is touching a horse. In the two-contrast context, we used conjoined elicitation questions (for example, Which boy is now blue and which boy is now green?') along with a visual stimulus that depicted two contrasts. The first contrast remained identical to the one in the one-contrast context. In addition to the first contrast, there were contrasting color changes (such as the boy turning blue versus the boy turning green in [2a]) or contrasting events (such as being photographed by the mouse or the bird as in [2b]).

We manipulated the grammatical role of the referent of the head noun (subject vs. object) in the targeted sentence by including visual scenes that elicited either subject- or object-modifying relative clauses, because we wanted to control for the grammatical role of the referent in the matrix clause. In subject-modifying relative clauses, the head noun is the subject of the matrix clause (see examples [Ia] and [2a]) and in object-modifying relative clauses, the head noun is the object of the matrix clause (see examples [Ib] and [2b]). When eliciting a subject-modifying relative clause, the referent undergoes the color change and consequently becomes the subject of the matrix clause. In examples [ra] and [2a] the targeted sentence reads The boy (who...) is now green. In contrast, when eliciting an object-modifying relative clause, the referent is the patient of the photographing done by a mouse (called Max) or a bird (called Tom). Hence, the referent becomes the object of the matrix clause and the targeted sentence reads Max is photographing the boy (who...), as for example in [Ib] and [2b].

The experiment was designed to elicit 60 responses from a total of 40 trials because we considered the two relative clauses elicited in the two-contrast context separately. The materials were intended to elicit 20 responses in the one-contrast context and 40 responses in the two-contrast context. The grammatical role of the referents was balanced ( 30 subjects, and 30 objects). In addition, we also controlled for the word order of the relative clause ( 42 subject-extracted, and I8 object-extracted relative clauses). Four-year-olds were tested on a reduced version of the experiment that included 30 trials.

\subsection{Procedure}

The children were asked to participate in a game where they had to describe to an experimenter what somebody was doing. When needed, the interaction between the experimenter and the child was mediated by a hand puppet. They sat in front of a computer screen which depicted the visual stimuli as two picture pairs. The laptop display was not visible to the hand puppet or the experimenter. An introductory picture displayed two characters participating in two similar events. While seeing this introductory picture, the participants listened to a pre-recorded female voice introducing the two characters and the two events. The experimenter then displayed 

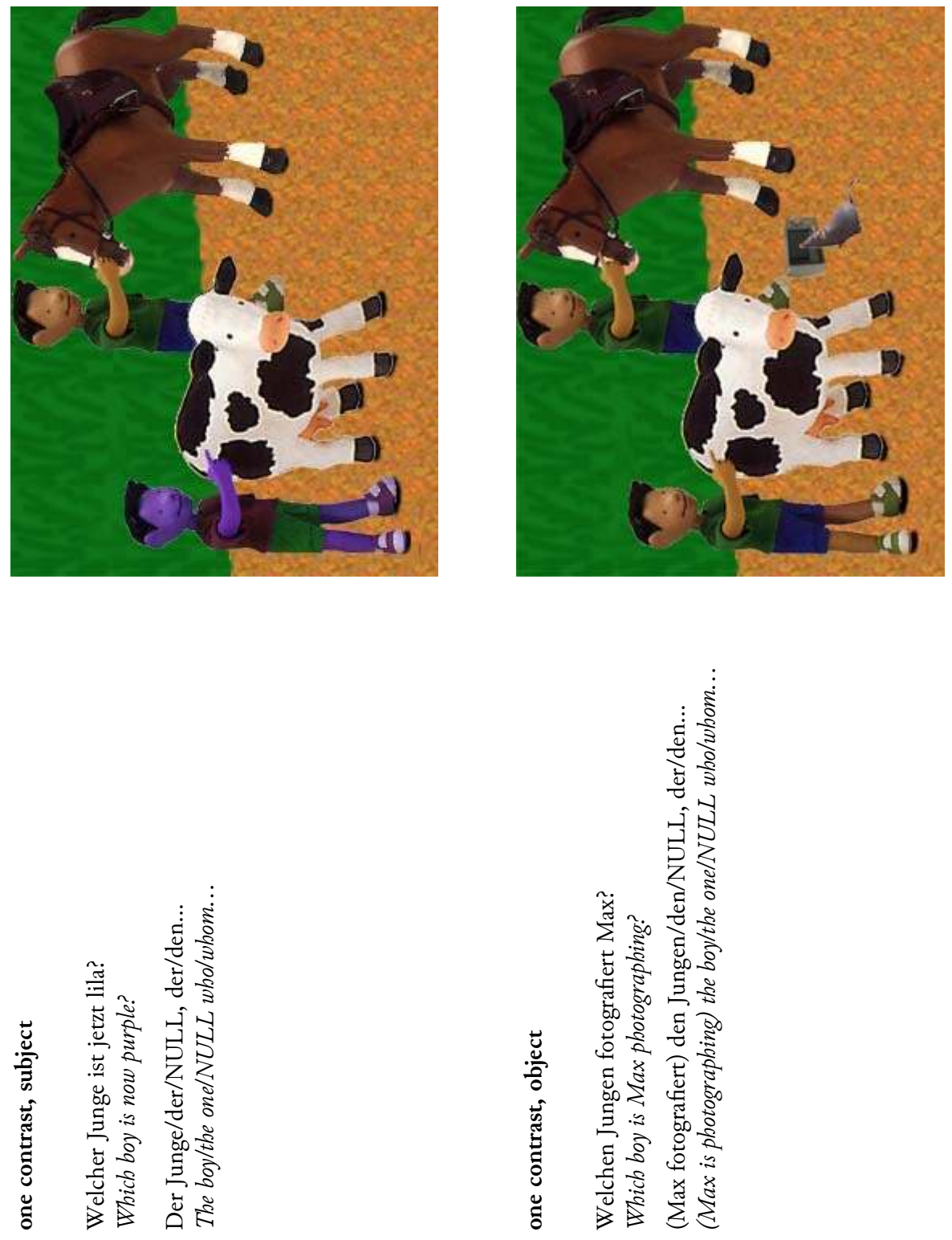

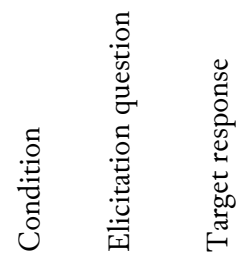

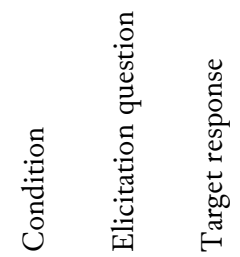

$\Xi$

올 

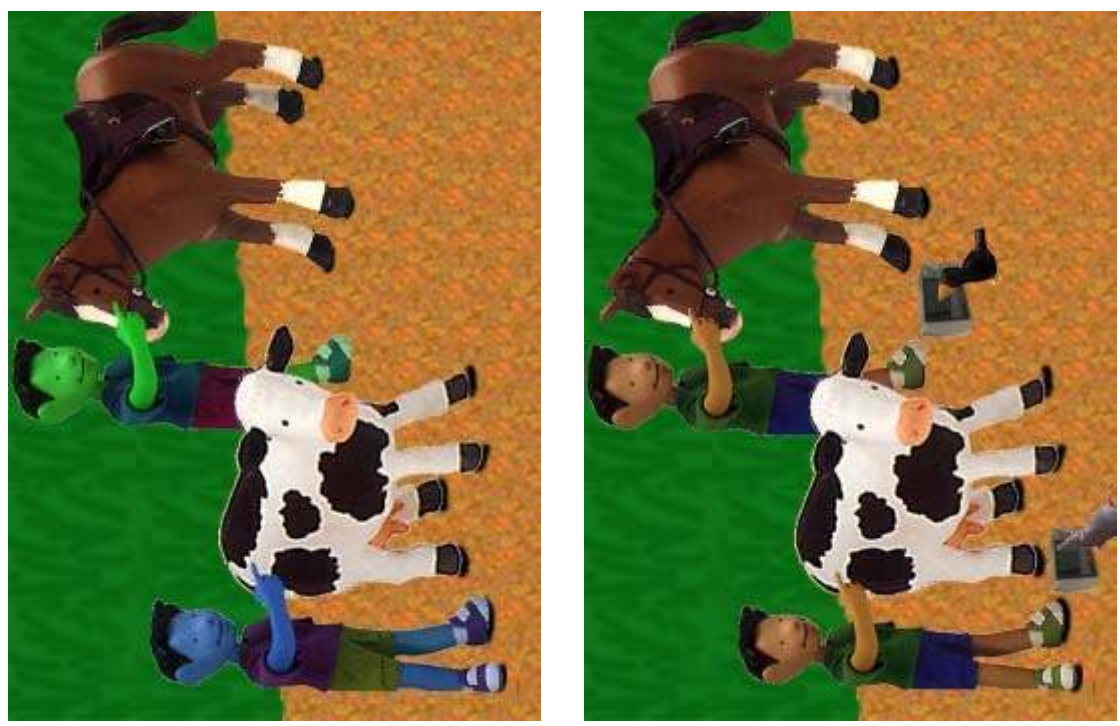

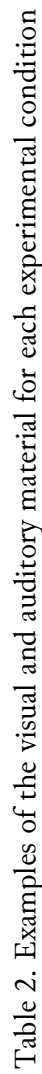
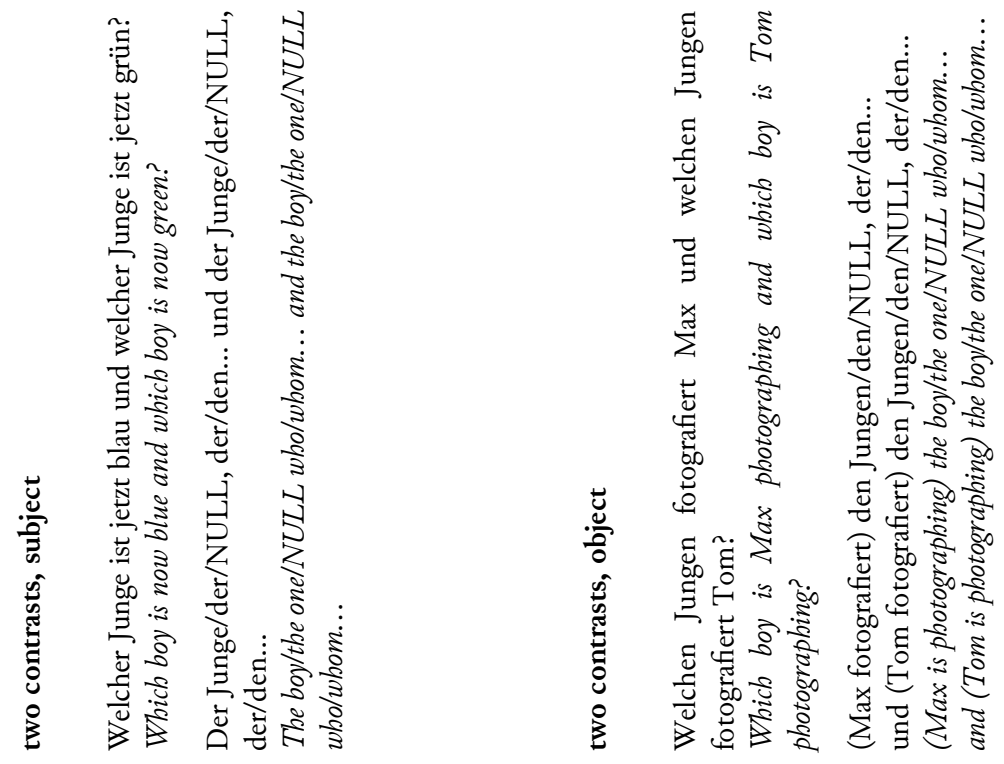

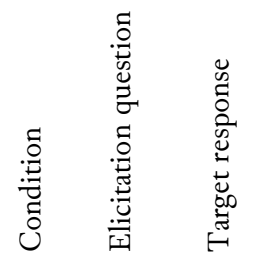

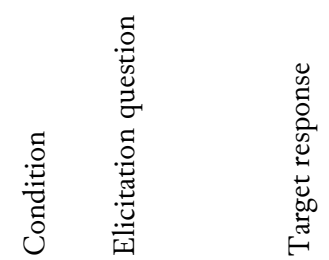

I

론 
via button press the subsequent picture, which represented the visual stimulus and was presented in combination with the pre-recorded elicitation question. A digital recorder recorded all prompted responses. The trials were presented in a pseudo-random order in two lists. A participant was always presented with only one of the two lists.

\subsection{Coding}

The data that was analyzed for this study is a subset of a larger data set for a study investigating the syntactic structure of elicited relative clauses (Adani et al., 2016). For the purpose of this study, we restricted the analysis to grammatical and pragmatically appropriate relative clauses. First, we decided to only include grammatical responses because we wanted to rule out the possibility that the language breakdown which is reflected in the ungrammaticality and pragmatic inappropriateness of an utterance may influence the referential choices. Pragmatic inappropriateness was defined as responses that are grammatical but nevertheless do not constitute a felicitous answer to the elicitation question. Second, we also excluded grammatical declarative sentences that were not a relative clause because we wanted to ensure that the explicitness of the head noun was not influenced by ambiguity avoidance. If the child produced a relative clause, the restrictive relative clause unambiguously enabled the identification of the target referent. Third, we also excluded all passives because the passive voice could possibly have independently influenced the referential choices. Three of the 40 trials elicited ambiguous relative clauses and were also not analyzed. The final data set contained 3,II8 responses of which 317 belonged to the SLI group. All responses were transcribed and coded for the type of referring expression produced for the relative clause head. The relative clause head corresponds to the referent that served as a response to the elicitation question. The participants produced either a lexical NP, a (demonstrative) pronoun (e.g., der, die, den in German), or a null element. Examples of responses for each type of referring expression are given in Table 3.

\begin{tabular}{|l|l|}
\hline Response type & Example from the actual data \\
\hline \multirow{2}{*}{ Lexical NP } & $\begin{array}{l}\text { Der Junge der die Kuh streicht ist jetzt lila. } \\
\text { the boy who the cow strokes is now purple } \\
\text { The boy who is stroking the cow is now purple. }\end{array}$ \\
\hline Pronoun & $\begin{array}{l}\text { Der der die Kuh berührt ist jetzt lila. } \\
\text { Demonstrative who the cow touches is now purple } \\
\text { The one who is touching the cow is now purple. }\end{array}$ \\
\hline \multirow{2}{*}{ Null element } & $\begin{array}{l}\text { Der die kleine Kuh antippt ist jetzt lila. } \\
\varnothing \text { who the little cow taps is now purple } \\
\text { Who is tapping the little cow is now purple. }\end{array}$ \\
\hline
\end{tabular}

Table 3. Examples of actual productions for each response type 


\section{Results}

We analyze the realization of the relative clause head noun, more specifically, whether it was a lexical NP or a less explicit expression (a pronoun or null element), using generalized linear-mixed models within the "lme4" package (Bates et al., 20I5) in R (version 3.2.2; R Development Core Team, 20I5). The random effects structure of the model includes an intercept and slope adjustment for subjects and an intercept adjustment for items. The correlations among the subject random effects were suppressed in order to optimize the random effects structure of the model according to Bates et al. (2015). The factor contrast level tests for a main effect by comparing responses in the one-contrast context (coded as $-\mathrm{I}$ ) to the two-contrast context (coded as I). The factor grammatical role (abbreviated as "gram role") tests for another main effect by comparing objects (coded as -I) to subjects (coded as I). We included their interaction as well. Contrast level and grammatical role were between-item factors. In order to compare children with SLI (coded as -I) to typically developing children (coded as I), we specify a group factor and its interactions with each of the two main effects of contrast levels and grammatical role, and their interaction. The continuous age variable relates to the typically developing children and has been included (as well as its interactions with the main effects) to reveal potential developmental changes.

Typically developing children produced $55 \%$ lexical NPs, $28 \%$ pronouns, and $17 \%$ null elements. Of the productions of children with SLI, $60 \%$ were lexical NPs, I $4 \%$ were pronouns, and $26 \%$ were null elements. We report the statistical analysis for the lexical NP productions. Hence, all occurrences that were not coded as lexical NP productions represent the selection of less explicit expressions (a pronoun or a null element).

We ran two separate models where the children with SLI were compared to the typically developing children on the basis of their chronological age (Model I) and their language age (Model 2). The models' output is provided in Table 4.

Both in the chronological-age comparison (Model I) and in the language-age comparison (Model 2), there is a main effect of contrast level, and a main effect of grammatical role, but an interaction of the two main effects is absent. The main effect of contrast level shows that, across groups, children produce more lexical NPs in the two-contrast context than in the one-contrast context. The main effect of grammatical role revealed that, across groups, children produced fewer lexical NPs for subjects than for objects. Despite the absence of a main effect for group in both models, the group difference interacted with the factor contrast level. See Figure I for illustration.

Pairwise comparisons for the first model, which takes the chronological age of the children into account, confirmed that the main effect of contrast level was present in both groups. However, there was a greater difference between the lower number of lexical NPs produced in the one-contrast context and the greater number in the two-contrast context among the typically developing children compared to the SLI group (TD: $\beta=2.42, S E=0.316, z=7.668, p<0.00$ I; SLI: $\beta=\mathrm{I} .35 \mathrm{I}$, $S E=0.536, z=2.519, p=0.012)$. 


\begin{tabular}{|c|c|c|c|c|c|c|c|c|}
\hline \multirow[b]{2}{*}{$\begin{array}{l}\text { Fixed } \\
\text { effects }\end{array}$} & \multicolumn{4}{|c|}{$\begin{array}{l}\text { Model I: } \\
\text { Comparing SLI to TD } \\
\text { on chronological age }\end{array}$} & \multicolumn{4}{|c|}{$\begin{array}{l}\text { Model 2: } \\
\text { Comparing SLI to TD } \\
\text { on language age }\end{array}$} \\
\hline & Estimate & $S E$ & $z$-value & $p$-value & Estimate & $S E$ & $z$-value & $p$-value \\
\hline (Intercept) & 0.067 & 0.299 & 0.224 & 0.823 & -0.313 & 0.305 & $-\mathrm{I} .026$ & 0.305 \\
\hline Age & 0.608 & 0.124 & 4.895 & $<0.001$ & 0.608 & 0.124 & 4.895 & $<0.001$ \\
\hline Group & 0.027 & 0.545 & 0.049 & $0.96 \mathrm{I}$ & -0.733 & 0.557 & $-I .315$ & $\mathrm{O} .188$ \\
\hline $\begin{array}{l}\text { Contrast } \\
\text { level }\end{array}$ & 1.885 & 0.359 & 5.257 & $<0.001$ & 2.083 & 0.367 & 5.674 & $<0.001$ \\
\hline Gram role & -0.817 & 0.405 & -2.018 & 0.044 & -0.822 & 0.413 & $-I .988$ & 0.047 \\
\hline $\begin{array}{l}\text { Contrast } \\
\text { level } x \\
\text { gram role }\end{array}$ & -0.128 & 0.658 & -0.194 & 0.846 & $0.23 \mathrm{I}$ & 0.672 & 0.344 & $0.73 \mathrm{I}$ \\
\hline $\begin{array}{l}\text { Age } \mathrm{x} \\
\text { contrast } \\
\text { level }\end{array}$ & -0.316 & 0.12 & $-2.64 I$ & 0.008 & -0.316 & 0.12 & $-2.64 \mathrm{I}$ & 0.008 \\
\hline $\begin{array}{l}\text { Age } x \\
\text { gram role }\end{array}$ & 0.007 & O.I47 & 0.045 & 0.964 & 0.007 & O.I47 & 0.045 & 0.964 \\
\hline $\begin{array}{l}\text { Group x } \\
\text { contrast } \\
\text { level }\end{array}$ & 1.069 & $0.5 \mathrm{I}$ & 2.098 & 0.036 & I.464 & $0.53 \mathrm{I}$ & 2.756 & 0.006 \\
\hline $\begin{array}{l}\text { Group x } \\
\text { gram role }\end{array}$ & -0.266 & 0.642 & $-0.4 \mathrm{I} 4$ & 0.679 & -0.274 & 0.663 & $-0.4 \mathrm{I} 4$ & 0.679 \\
\hline $\begin{array}{l}\text { Age } x \\
\text { contrast } \\
\text { level } x \\
\text { gram role }\end{array}$ & -0.575 & 0.208 & -2.765 & 0.006 & -0.575 & 0.208 & -2.765 & 0.006 \\
\hline $\begin{array}{l}\text { Group x } \\
\text { contrast } \\
\text { level x } \\
\text { gram role }\end{array}$ & I. $4 \mathrm{I} 4$ & 0.873 & I. $62 \mathrm{I}$ & 0.105 & 2.133 & 0.916 & 2.329 & 0.020 \\
\hline
\end{tabular}

Table 4. Output of the statistical analyses ${ }^{2}$

Pairwise comparisons for the second model confirm that the main effect of contrast level is still present when taking the language age of the SLI group into account (TD: $\beta=2.815, S E=0.351, z=8.023, p<0.001$; SLI: $\beta=1.351, S E=0.536$, $z=2.519, p=0.012)$. Consistent with the first model, the effect of contrast level

2. $\mathrm{SLI}=$ Specific Language Impairment $; \mathrm{TD}=$ typically developing controls; gram role = grammatical role 


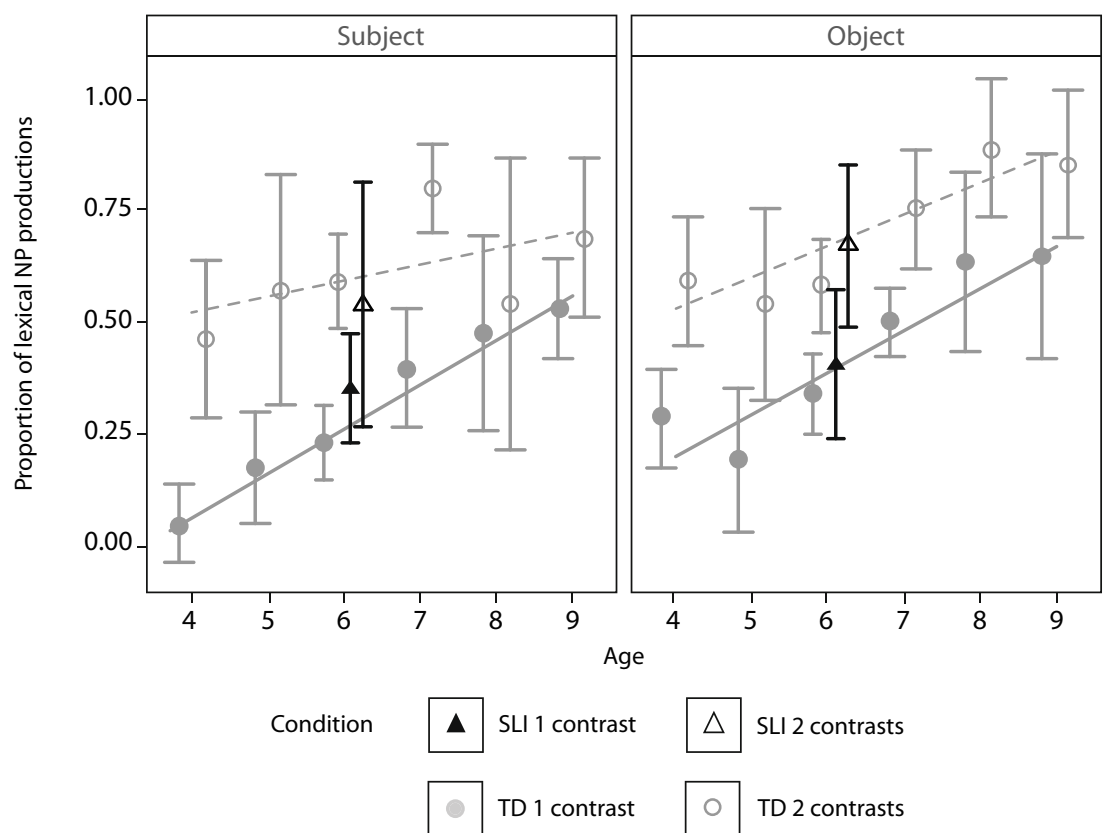

Figure 1. Mean proportions of lexical NPs produced, comparing SLI and TD groups on the basis of chronological age; error bars indicate two standard errors ${ }^{3}$

is smaller within the SLI group compared to the typically developing children. Figure 2 illustrates that children with SLI produce more lexical NPs in the onecontrast context compared to typically developing children of age 5 . In addition, we also observe a three-way interaction of group, contrast level, and grammatical role. Regarding the performance of the typically developing children, pairwise comparisons show that the effect of contrast levels is evident in the lexical NP productions of the typically developing children for subject and object heads (TD: subjects: $\beta=3.464, S E=0.508, z=6.815, p<0.001$; TD: objects: $\beta=2.166$, $S E=0.446, z=4.86, p<0.00 \mathrm{I})$, but that there is a greater difference between contrast levels among subjects than objects. Pairwise comparisons for the SLI group reveal the effect of contrast levels for objects but the effect is absent for subjects (SLI: subjects: $\beta=0.933, S E=0.713, z=1.308, p=0.191$; SLI: objects: $\beta=1.768$, $S E=0.719, z=2.459, p=0.014)$. Figure 2 shows that the absence of the contrast level effect in subjects results from the high variability of lexical NP productions for subjects in the two-contrast context by the SLI group.

3. $\mathrm{SLI}=$ Specific Language Impairment $\mathrm{TD}=$ typically developing children; $\mathrm{I}$ contrast $=$ one-contrast condition; 2 contrasts $=$ two-contrast condition; Subject $=$ subject of the uttered sentence; Object $=$ object of the uttered sentence. 


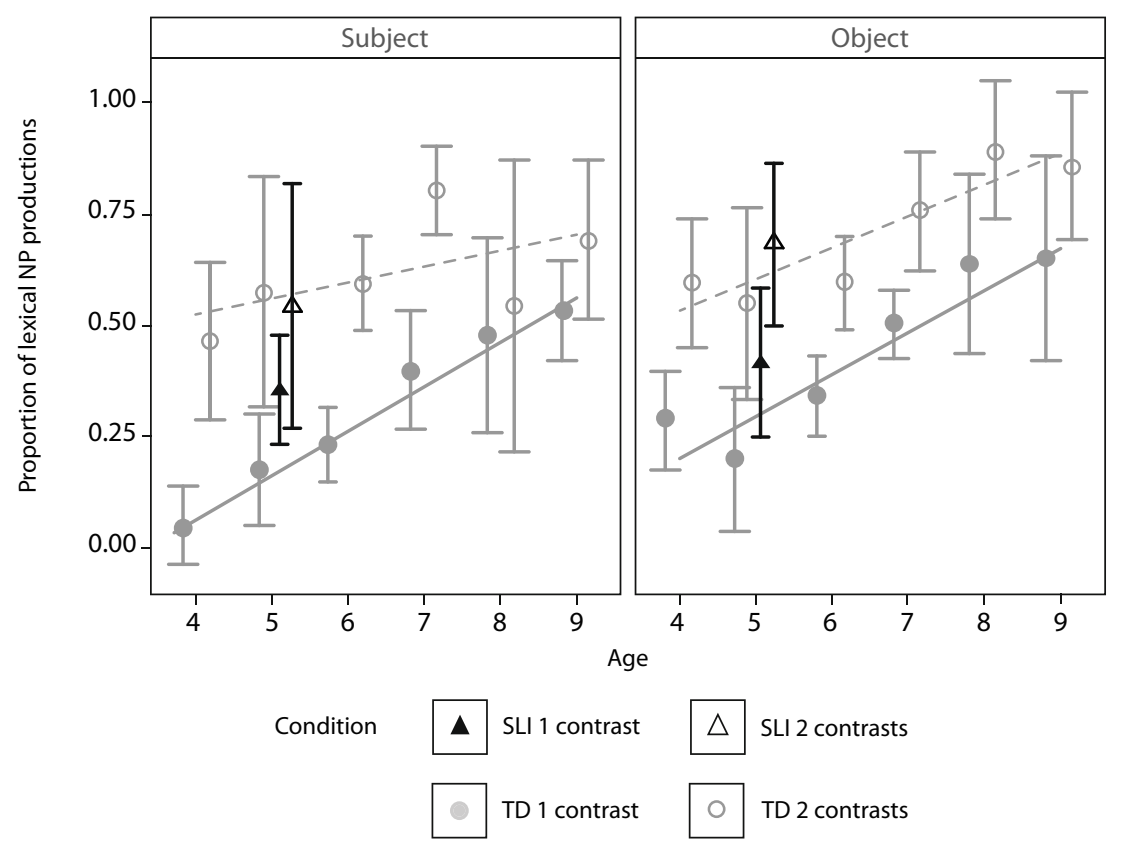

Figure 2. Mean proportions of lexical NPs produced, comparing SLI and TD groups on the basis of the language age of the SLI group; error bars indicate two standard errors ${ }^{4}$

The effect of age reveals that typically developing children produce an increasing number of lexical NPs as they get older. The two-way interaction of age and contrast level shows that the difference between the two levels of contrast decreases as the children become older. The three-way interaction of age, contrast level, and grammatical role specifies further that the difference between the lexical NPs produced according to the experimental factors decreases more dramatically for subjects than for objects (subjects: $\beta=-0.603, S E=0.166, z=-3.626, p<0.001$; objects: $\beta=-0.029, S E=0.150, z=-0.190, p=0.849)$.

\section{Discussion}

We have reported a production experiment that manipulated levels of contrast and the grammatical role of the intended referent at the sentence level to elicit referring expressions of varying explicitness. We will discuss the implications of our results separately for the two participant groups, starting with typical development and turning later to SLI.

4. $\quad$ SLI $=$ Specific Language Impairment; $\mathrm{TD}=$ typically developing children; $\mathrm{I}$ contrast $=$ one-contrast condition; 2 contrasts $=$ two-contrast condition; Subject $=$ subject of the uttered sentence; Object $=$ object of the uttered sentence. 
Our experiment demonstrates that children adapt their selection of referring expressions to levels of contrast in the discourse and the grammatical role of the referent in the sentence. In the presence of two contrasts, children are more likely to produce lexical NPs, hence, a referring expression of the more explicit type, than in the presence of only one contrast. This result supports our prediction about the influence of contrast levels on the production of referring expressions and is consistent with earlier reports on the influence of referent availability on children's production of referring expressions (e.g., Serratrice, 2008 and 2013). The children in our study also showed sensitivity to the grammatical role of the referent and produced fewer explicit referring expressions for subject head nouns than for object head nouns. This finding confirms our prediction about the influence of grammatical role and corroborates previous findings of children's preference for less explicit expressions for subjects (e.g., Bittner, 2007; Theakston, 2012) in comparison to objects.

For typical development, we also show that the likelihood of producing lexical NPs in the presence of contrasts is subject to a developmental trend. Older children produce more lexical NPs than younger children, but this increase is modulated by levels of contrast. The effect of contrast is greater in the younger age range (i.e., 4 to 6 years), than in the older age range (i.e., 7 to ro years), and more specifically so for subjects than for objects.

We argue that the effect of contrast level arises from competition in the children's discourse model. The evidence for the increased production of more explicit expressions is based on situations where the production of explicit forms cannot be explained by the avoidance of ambiguity (because the use of a restrictive relative clause specified which referent was meant). Hence, we are led to attribute the increase in lexical NPs to competition effects (according to Arnold, 2008). We conclude that the increase in contrast levels leads to similar levels of activation of referents in the speakers' discourse representation. The similarity of the activation levels in turn makes the referents less accessible. Since less accessible referents are typically referred to with more explicit forms of reference, the decreased accessibility leads to the production of more lexical NPs (e.g., the boy, the purple horse). Our findings corroborate previous findings on children's early sensitivity to the presence of a potential competitor in the discourse or perceptual context (see Allen et al., 2008; Allen et al., 20I5). Competition effects that are evoked by the perceptual presence of a potential competitor have been shown for children before (Serratrice, 2008 and 2013). We show in addition that an increase in contrast levels can also lead to competition effects.

Children's productions are also influenced by the grammatical role of the referent in the uttered sentence. They produce more lexical NPs for objects than for subjects. This finding is consistent with the extensive evidence that the prominence of subjects leads to high accessibility and that subjects are as a consequence more likely to be pronominalized or omitted (Theakston, 20I2) than objects. We want to point out that our experiment cannot distinguish whether the crucial factor is the 
grammatical role in the preceding sentence, the question in our experiment, or the grammatical role the referent occupies in the sentence uttered by the participant. In our experiment, the grammatical role of the intended referent was either subject of the question (e.g., Which boy is now green?) and of the uttered matrix clause (e.g., The boy who... is now green), or object of the question (e.g., Which boy is Max photographing?) and of the uttered matrix clause (e.g., Max is photographing the boy who...). It is plausible that both the grammatical role of the referent of the preceding question, and the grammatical role of the referent in the matrix clause contribute to the decrease in very explicit expressions for subjects compared to objects because both factors have been shown to influence referential choices in these ways (Brennan, 1995).

We find that the production of more explicit forms undergoes a developmental change. Our finding is consistent with previous research that also showed an increase in lexical NP productions among older children (e.g., Bittner, 2007; Serratrice, 2008). Moreover, our findings also indicate that the contrast effect changes with development. We relate this effect to the salience of contrasts, which enables even very young children to perceive them and adjust their referential choices to the contrast (Wittek \& Tomasello, 2005). We argue that the contrasts can serve as a starting point for the acquisition of subtler information-structural notions, such as focus and topic. Because all references that we elicited were direct responses to the wh-element in the elicitation question, they were all focal. For our types of elicited responses, one could argue that we elicited contrastive foci in the onecontrast context and contrastive topics in the two-contrast context (Molnár, 2006). Although we explicitly avoided ambiguity in our experimental design, contrasts can, in principal, also help children become more sensitive to potential ambiguity in their references, because ambiguity potentially arises in those situations where there is more than one potential referent available (cf. Allen et al., 20I5).

The developmental change also provides an explanation of why children sometimes differ from adults in the explicitness of their referring expressions. Children have been argued not to take ambiguity into account as much as adults do (Hendriks et al., 20I4). Our results suggest that young children may also be differently affected by information-structural notions such as contrast, and this might contribute to the likelihood of producing less explicit expressions.

Turning to children with SLI, we find referential choices that are consistent with the patterns shown by the typically developing children. First, contrast levels play an important role in their selection of referring expressions. They respond to the increase in contrast levels similarly to their controls with an increase in lexical NP productions.

Consistent with our conclusion for typically developing children, we interpret the increase in lexical NP productions as a consequence of competition effects arising in their discourse representation. Children with SLI monitor the activation statuses of referents in the discourse and are aware of the presence of a potential 
competitor. This finding is consistent with their preference for lexical NPs for reintroducing referents as in the van der Lely (1997) study. In this respect, we demonstrate that the language impairment does not affect the sensitivity to the presence of contrasts. This effect might not be surprising given the robustness and the early onset of contrast effects in typical development (Graf et al., 2015; Wittek \& Tomasello, 2005). It also confirms our predictions with regard to the children with SLI and supports the claim that their abilities are spared with respect to a pragmatic factor such as contrast.

Still, we observe a numerically smaller effect of contrast level in the group of children with SLI. When comparing the children with SLI to the typically developing children on the basis of their language age, the SLI group appears to differ from their controls in terms of more explicit responses in the one-contrast context while behaving very similarly in the two-contrast context. When van der Lely (1997) also observed a tendency of children with SLI to produce more lexical NPs for the reintroduction of referents, she interpreted this observation as reflecting more mature referential choices compared to the language-matched controls and speculated that children with SLI may have a greater awareness for linguistic forms from the language therapy experience. This in turn may lead to the increased production of lexical NPs. It is worth mentioning that in her study all controls were language-matched (albeit based on different linguistic abilities). Norbury and Bishop (2003) also reported a higher production rate of lexical NPs relative to pronouns for maintaining reference by children with SLI compared to chronological-age-matched controls, which we also consider as evidence for over-explicitness. We could have come to a similar conclusion to van der Lely if we had not included the comparison to the typically developing children on the basis of the chronological age. This comparison tells us that the SLI children behave as expected on the basis of their average chronological age in the one-contrast context. Bearing this in mind, it is not surprising that they differ from the typically developing children in the language-age comparison because they are in fact older and behave as the older children in this condition do (therefore showing "more mature" referential choices according to van der Lely [1997]). An important methodological implication of this result is the need to control for the chronological age of the clinical group, as well as to consider the developmental trajectory of a phenomenon. This is what de Weck and Jullien (2013) did and they also observed that younger children with SLI differed from controls with respect to appropriate introductions of referents while older children with SLI did not.

How can we account for the difference with regard to the influence of contrast levels between the production rates of lexical NPs of children with SLI and those produced by typically developing children? As outlined in the introduction, the selection of an appropriate expression crucially depends on the speaker's own model of the current discourse. The speaker needs to model the activation status of a referent in order to determine the degree of explicitness that is necessary for the expression to be appropriate in a given situation. Hence, the difference in production rates between the SLI and the TD groups might reflect a difference in 
how the two groups maintain the activation status of referents in their discourse representation. It has been previously assumed in the literature that weaker verbal working memory abilities affect maintenance of the activation status of referents in the discourse representation, which in turn can lead to differences in the production rates of referring expressions. According to Hendriks et al. (2014), weaker verbal working memory abilities influence the production of pronouns (and hence, explain the production of ambiguous pronouns). Arnold et al. (2009) have also discussed this idea when accounting for overexplicit expressions. SLI has been characterized by weaker verbal working memory abilities (e.g., Archibald \& Gathercole, 2006). We think the idea that differences in the production rates of referring expressions hinge on weaker verbal working memory abilities is consistent with the idea that children with SLI have difficulties maintaining the activation status of referents in their discourse representation. We argue that those difficulties maintaining the activation status might explain the difference between lexical NP production by children with SLI and that by typically developing children which we observed in relation to contrast levels in our sample and which has been previously observed in narrative discourses (i.e., Norbury \& Bishop, 2003; van der Lely, 1997).

Turning to grammatical role, we do not find any evidence for a difference between children with SLI and typically developing children with respect to how they take into account the grammatical role of the referent. This finding is unexpected under the hypothesis that the language impairment predominantly influences factors that are grammatical. Our findings point in the direction that children with SLI and age-matched typically developing children prefer to produce less explicit expressions for subjects than for objects. They treat subjects as more accessible than objects (see also Schelletter \& Leinonen, 2003). What might have contributed to this result is the fact that the elicitation question in our experiment constrained the targeted grammatical role of the referent. When attempting to produce a felicitous answer to our elicitation question, our participants were not free to determine the grammatical role of the referent because this was already determined by whether this was a subject or object which-question.

How can we reconcile reported differences between children with SLI and typically developing children in the current experiment as well as in previous work? We know that children with SLI have difficulties in constructing coherent discourses, which may exacerbate their referencing abilities (Norbury et al., 20I4). Several studies have reported, for example, that children with SLI have difficulties producing appropriate narrative discourses beyond the appropriateness of their referential choices (e.g., Norbury \& Bishop, 2003). The difficulties range from sentence complexity, use of connectives, and use of internal state language to aspects of narrative organization and complexity (Tribushinina et al., 2015a and 2015b; Tsimpli et al., 2016). In our study, we concentrate on two very narrowly defined pragmatic and grammatical factors, contrast and grammatical role, respectively. We used a controlled elicitation task, which revealed that children with SLI perform quite similarly to typically developing children when the accessibility of referents 
is controlled for in the materials. We consider this finding to indicate that the pragmatic and grammatical basis for determining the accessibility of referents with respect to contrast and grammatical role as determining factors and, in turn, the mapping between the accessibility of a referent and the explicitness of the referring expression are spared in SLI (Schaeffer, 2012; van der Lely, 1997). These results do not necessarily bear on the much wider question as to whether other discourserelated abilities are impaired in SLI or not. The studies cited above indicate that several aspects of discourse are likely to be affected.

Future work needs to clarify how difficulties with maintaining the activation status of referents in the discourse model influence the performance of children with SLI on discourse-related phenomena. As mentioned above, it has been proposed that differences between the production rates of expressions with varying degrees of explicitness might hinge on verbal working memory abilities, and future work needs to clarify exactly how verbal working memory abilities in SLI relate to their referential choices. It remains an interesting question for further study of SLI whether difficulties with maintaining activation status affect not only the explicitness of referential choices, but also more globally the organization of coherent discourses in conversational speech or narratives.

With a controlled experimental elicitation task, we show that children with SLI predominantly exhibit similar preferences for the explicitness of expressions as determined by contrast and grammatical role to those of typically developing children. We observe a slight difference to typically developing children in contexts that involve greater cognitive processing demands. Hence, the explicitness of referential choices of children with SLI appears to be largely unaffected by the language impairment and differences can be explained as consequences of difficulties in maintaining the activation status of referents in the discourse.

\section{Acknowledgements}

The work presented here was funded by the German Research Foundation (DFG) and carried out within the Collaborative Research Center SFB 632 Information Structure project $\mathrm{C}_{3}$. We would like to thank Yair Haendler for his support with the data management, Antje Sauermann, the audiences at "Petra Hendrik's Acquisition Colloquium", at the "RefNet Workshop 20I4", and at the SLI workshop at the "Experimental Psycholinguistics Conference 20I4" for constructive discussions, the two anonymous reviewers, and the editors for their helpful comments on the manuscript. We thank Astrid Fröhling (ZAPP Potsdam), Dr. Jenny von Frankenberg (ZAPP Berlin), Daniela Dinter (Logopädische Praxis Daniela Dinter), Anja Truckenbrodt (Praxis für Logopädie Truckenbrodt), and their teams for their invaluable support in recruiting children with SLI. We are very grateful to all children and their parents for their participation in our study, as well as to their (kindergarten) teachers, and therapists for their support. We also thank Andrea Zukowski for making her experimental material available to us. 


\section{References}

Adani, F., Stegenwallner-Schütz, M., Haendler, Y. \& Zukowski, A. 2oi6. Elicited Production of Relative Clauses in German: Evidence from Typically Developing Children and Children with Specific Language Impairment. First Language 36 (3): 203-227.

Allen, S., Hughes, M. \& Skarabela, B. 20I5. The Role of Cognitive Accessibility in Children's Referential Choice. In L. Serratrice \& S. Allen (eds.), The Acquisition of Reference. Amsterdam: J. Benjamins: I23-154.

Allen, S., Skarabela, B. \& Hughes, M. 2008. Using Corpora to Examine Discourse Effects in Syntax. In H. Behrens (ed.), Corpora in Language Acquisition Research: History, Methods, Perspectives. Amsterdam: J. Benjamins: 99-I37.

Archibald, L.M.D. \& Gathercole, S.E. 2006. Short-Term and Working Memory in Specific Language Impairment. International Journal of Language and Communication Disorders 4I (6): 675-693.

Ariel, M. 1990. Accessing Noun-Phrase Antecedents. London - New York: Routledge.

Ariel, M. 200I. Accessibility Theory: An Overview. In T. Sanders, J. Schilperoord \& W. Spooren (eds.), Text Representation: Linguistic and Psycholinguistic Aspects. Amsterdam: J. Benjamins: 29-88.

Arnold, J.E. 200I. The Effect of Thematic Roles on Pronoun Use and Frequency of Reference Continuation. Discourse Processes 3I (2): I37-I62.

Arnold, J.E. 2008. Reference Production: Production-Internal and Addressee-Oriented Processes. Language and Cognitive Processes 23 (4): 495-527.

Arnold, J.E., Bennetto, L. \& Diehl, J.J. 2009. Reference Production in Young Speakers with and without Autism: Effects of Discourse Status and Processing Constraints. Cognition IIO (2): I3I-I46.

Arnold, J.E. \& Griffin, Z.M. 2007. The Effect of Additional Characters on Choice of Referring Expression: Everyone Counts. Journal of Memory and Language 56 (4): 52I-536.

Bates, D., Kliegl, R., Vasishth, S. \& BaAyen, H. 20I5. Parsimonious Mixed Models. I-27. Available online: http://arxiv.org/abs/I506.04967.

Bates, D., Mächler, M., Bolker, B. \& Walker, S. 2015. Fitting Linear Mixed-Effects Models Using "Ime4". Journal of Statistical Software 67 (I): I-48.

Bishop, D.V.M. 1997. Uncommon Understanding: Development and Disorders of Language Comprebension in Children. Hove: Psychology Press.

Bishop, D.V.M. \& AdAms, C. I99I. What Do Referential Communication Tasks Measure? A Study of Children with Specific Language Impairment. Applied Psycholinguistics I2 (2): $199-215$.

Bittner, D. 2007. Influence of Animacy and Grammatical Role on Production and Comprehension of Intersentential Pronouns in German LI-Acquisition. In D. BitTNER \& N. Gargarina (eds.), Intersentential Pronominal Reference in Child and Adult Language. ZAS Papers in Linguistics 48. Berlin: Zentrum für Allgemeine Sprachwissenschaft (ZAS): I03-I38.

Brennan, S.E. 1995. Centering Attention in Discourse. Language and Cognitive Processes IO (2): 137-167. 
Campbell, A.L., Brooks, P. \& Tomasello, M. 2000. Factors Affecting Young Children's Use of Pronouns as Referring Expressions. Journal of Speech, Language, and Hearing Research 43 (6): 1337-1349.

Chafe, W.L. 1976. Givenness, Contrastiveness, Definiteness, Subjects, Topics and the Point of View. In C.N. Li (ed.), Subject and Topic. New York - London: Academic Press: 27-55.

Davies, C., Andrés-Roqueta, C. \& Norbury, C.F. 20I6. Referring Expressions and Structural Language Abilities in Children with Specific Language Impairment: A Pragmatic Tolerance Account. Journal of Experimental Child Psychology I44: 98-II3.

De CAT, C. 20II. Information Tracking and Encoding in Early Lr: Linguistic Competence vs. Cognitive Limitations. Journal of Child Language 38 (4): 828-86o.

De CAt, C. 2013. Egocentric Definiteness Errors and Perspective Evaluation in Preschool Children. Journal of Pragmatics 56: 58-69.

DE WECK, G. \& Jullien, S. 20I3. How Do French-Speaking Children with Specific Language Impairment First Mention a Referent in Storytelling? Between Reference and Grammar. Journal of Pragmatics 56: 70-87.

Du BoIs, J.W. 1987. The Discourse Basis of Ergativity. Language 63 (4): $805-855$.

FARrant, B.M., Fletcher, J. \& MAYBery, M.T. 2006. Specific Language Impairment, Theory of Mind, and Visual Perspective Taking: Evidence for Simulation Theory and the Developmental Role of Language. Child Development 77 (6): I842-I853.

Fukumura, K., van Gompel, R.P.G. \& Pickering, M.J. 2oio. The Use of Visual Context during the Production of Referring Expressions. Quarterly Journal of Experimental Psychology 63 (9): I700-I7I5.

Gatt, A., Krahmer, E., van Deemter, K. \& van Gompel, R.P.G. 20I4. Models and Empirical Data for the Production of Referring Expressions. Language, Cognition and Neuroscience 29 (8): 899-9II.

GLüCK, C.W. 2007. Wortschatz- und Wortfindungstest für 6- bis Io-Jäbrige (WWT 6-Io). Munich: Elsevier.

Graf, E., Theakston, A., Lieven, E. \& Tomasello, M. 2015. Subject and Object Omission in Children's Early Transitive Constructions: A Discourse-Pragmatic Approach. Applied Psycholinguistics 36 (3): 70I-727.

Grob, A., Meyer, C.S. \& Hagmann-von Arx, P. 2009. Intelligence and Development Scales (IDS) / Intelligenz- und Entwicklungsskalen für Kinder von 5-Io Jabren. Bern: Verlag Hans Huber.

Grosz, B.J., Joshi, A.K. \& Weinstein, S. 1995. Centering: A Framework for Modeling the Local Coherence of Discourse. Computational Linguistics 2I (2): 203-225.

Gundel, J.K., Hedberg, N. \& Zacharski, R. 1993. Cognitive Status and the Form of Referring Expressions in Discourse. Language 69 (2): 274-307.

Gundel, J.K., HedBERG, N. \& ZaCHARsKi, R. 20I2. Underspecification of Cognitive Status in Reference Production: Some Empirical Predictions. Topics in Cognitive Science 4 (2): 249-268.

Gundel, J.K. \& Johnson, K. 2013. Children's Use of Referring Expressions in Spontaneous Discourse: Implications for Theory of Mind Development. Journal of Pragmatics 56: 43-57. 
Gundel, J.K., Ntelitheos, D. \& Kowalsky, M. 2007. Children's Use of Referring Expressions: Some Implications for Theory of Mind. In D. BITTNER \& N. GARGARINA (eds.), Intersentential Pronominal Reference in Child and Adult Language. ZAS Papers in Linguistics 48. Berlin: Zentrum für Allgemeine Sprachwissenschaft (ZAS): I-2I.

Hendriks, P., Koster, C. \& Hoeks, J.C.J. 20I4. Referential Choice across the Lifespan: Why Children and Elderly Adults Produce Ambiguous Pronouns. Language, Cognition and Neuroscience 29 (4): 39I-407.

Hickmann, M., Hendriks, H., Roland, F. \& Liang, J. 1996. The Marking of New Information in Children's Narratives: A Comparison of English, French, German and Mandarin Chinese. Journal of Child Language 23 (3): 59I-6I9.

Kail, M. \& Hickmann, M. I992. French Children's Ability to Introduce Referents in Narratives as a Function of Mutual Knowledge. First Language I2 (34): 73-94.

Kauschke, C. \& Siegmüller, J. 2002. Patholinguistische Diagnostik bei Sprachentwicklungsstörungen. Munich: Elsevier.

LeOnard, L.B. 1998. Children with Specific Language Impairment. Cambridge - London: MIT Press.

Matthews, D., Lieven, E., Theakston, A. \& Tomasello, M. 2006. The Effect of Perceptual Availability and Prior Discourse on Young Children's Use of Referring Expressions. Applied Psycholinguistics 27 (3): 403-422.

Miller, C.A. 2004. False Belief and Sentence Complement Performance in Children with Specific Language Impairment. International Journal of Language and Communication Disorders 39 (2): 19I-2I3.

Molnár, V. 2006. On Different Kinds of Contrast. Studies in Generative Grammar 82: 197-233.

Norbury, C.F. \& Bishop, D.V.M. 2003. Narrative Skills of Children with Communication Impairments. International Journal of Language and Communication Disorders 38 (3): 287-3I3.

Norbury, C.F., Gemmell, T. \& PAul, R. 20I4. Pragmatics Abilities in Narrative Production: A Cross-Disorder Comparison. Journal of Child Language 4I (3): 485-5IO.

Petermann, F., Fröhlich, L.P. \& Metz, D. zoio. SET 5-IO-Sprachstandserbebungstest für Kinder im Alter zwischen 5 und Io Jabren. Göttingen: Hogrefe.

R Development Core Team 20I5. The R Project for Statistical Computing. Vienna: R Foundation for Statistical Computing. Available online: http://www.R-project.org.

SCHAEFFER, J. 20I2. Specific Language Impairment - Evidence for the Division of Labor and the Interaction between Grammar and Pragmatics. Saarbrücken: Lambert Academic Publishing.

Schelletter, C. \& Leinonen, E. 2003. Normal and Language-Impaired Children's Use of Reference: Syntactic versus Pragmatic Processing. Clinical Linguistics and Phonetics $17(4-5): 335-343$.

Serratrice, L. 2008. The Role of Discourse and Perceptual Cues in the Choice of Referential Expressions in English Preschoolers, School-Age Children, and Adults. Language Learning and Development 4 (4): 309-332. 
Serratrice, L. 2013. The Role of Number of Referents and Animacy in Children's Use of Pronouns. Journal of Pragmatics 56: 31-42.

Siegmüller, J., Kauschke, C., van Minnen, S. \& Bittner, D. 20II. Test zum Satzverstehen von Kindern. Eine profilorientierte Diagnostik der Syntax. Munich: Elsevier.

Stegenwallner-Schütz, M. \& Adani, F. 20I4. How Can the Study of Developmental Disorders Inform Linguistic Theory about Information Structure? Grazer Linguistische Schriften 8I: 69-86.

Theakston, A.L. 20I2. "The Spotty Cow Tickled the Pig with a Curly Tail”: How Do Sentence Position, Preferred Argument Structure, and Referential Complexity Affect Children's and Adults' Choice of Referring Expression? Applied Psycholinguistics 33 (4): 69I-724.

Thomas, M.S.C., Annaz, D., Ansari, D., Scerif, G., Jarrold, C. \& Karmiloff-Smith, A. 2009. Using Developmental Trajectories to Understand Developmental Disorders. Journal of Speech, Language, and Hearing Research 52 (2): 336-358.

Tribushinina, E., Dubinkina, E., Sanders, T. 20isa. Can Connective Use Differentiate between Children with and without Specific Language Impairment? First Language $35(\mathrm{I}): 3-26$.

Tribushinina, E., Mak, W.M., Andreiushina, E., Dubinkina, E. \& Sanders, T. 20i5b. Connective Use in the Narratives of Bilingual Children and Monolingual Children with SLI. Bilingualism: Language and Cognition. "FirstView Articles". I-I6.

Tsimpli, I.M., Peristeri, E. \& ANDreou, M. 20I6. Narrative Production in Monolingual and Bilingual Children with Specific Language Impairment. Applied Psycholinguistics 37 (I): $195-216$.

VAN DER LELY, H.K.J. 1997. Narrative Discourse in Grammatical Specific Language Impaired Children: A Modular Language Deficit? Journal of Child Language 24 (I): 22I-256.

VAN DER LeLY, H.K.J. 2005. Domain-Specific Cognitive Systems: Insight from GrammaticalSLI. Trends in Cognitive Sciences 9 (2): 53-59.

Wittek, A. \& Tomasello, M. 2005. Young Children's Sensitivity to Listener Knowledge and Perceptual Context in Choosing Referring Expressions. Applied Psycholinguistics $26(4): 54 \mathrm{I}-558$.

Zukowski, A. 2009. Elicited Production of Relative Clauses in Children with Williams Syndrome. Language and Cognitive Processes 24 (I): I-43. 